\title{
Annual Reproductive Cycle of Acheilognathus rhombeus, in Korea
}

\author{
Se-Un Ki ${ }^{1,2}$, Kang-Hee Kho ${ }^{1}$, and ${ }^{\dagger}$ Won-Kyo Lee ${ }^{1}$ \\ ${ }^{1}$ Dept. of Aquaculture, Chonnam National University, Yeosu 59626, Korea \\ ${ }^{2}$ Jeollanamdo Institute of Ocean and Fisheries Technology, Wando 59116, Korea
}

\begin{abstract}
In this study, an experiment was conducted to investigate the annual reproductive cycle of a Korean flat bittering, Acheilognathus rhombeus, from Ogok-myeon located in Seomjin River. The reproductive cycle was examined histologically regarding water temperature and day length of the habitat, the gonadosomatic index (GSI), and developmental characteristics of female and male gonads. The maximum GSI was found to be $3.50 \pm 0.53$ and $1.36 \pm 0.14$ for females and males, respectively, when the water temperature and day light was $16.9^{\circ} \mathrm{C}$ and 11.3 hours, respectively in October 2018 . On the other hand, the minimum GSI was found to be $0.16 \pm 0.09$ and $0.69 \pm 0.15$ for males and females in December 2018 and February 2019, respectively. The ovipositor of females appeared from August to November 2018. We compared and calculated the stages of germ cell developmental characteristics in the testis and ovaries to determine the reproductive cycle. According to the result, we classified the female A. rhombeus reproductive cycle into four phases, which are ripe and spawning phase (October), degenerative phase (November to December), growing phase (January to March) and mature phase (April to September). The annual reproductive cycle of male A. rhombeus was categorized into four phases: mature phase (June to October), degenerative phase (November to March), resting phase (April) and growing phase (May). The Korean flat bittering is an autumn-spawner as the main spawning season in October. In male, testicular spermatogonia appeared all yearround, and the ripe and releasing phase, which is characteristics of the spawning season in other fish, did not appear.
\end{abstract}

Key words : Acheilognathus rhombeus, Gonadosomatic index (GSI), Spawning, Reproductive cycle

\section{INTRODUCTION}

There are about forty species of Acheilognathinae subfamily fishes in the world. Fourteen species under two genera are found in South Korea. 9 out of 14 Acheilognathinae subfamily species are endemic in South Korea (Kim et al., 2005). Among them, Rhodeus hondae has been already reported to be extinct. Since the Acheilognathinae subfamily fishes usually inhabit freshwater, they are highly vulnerable to development and industrialization. Not only habitat protection but also defining reproductive characteristics are essential to conserve species.

In the aquaculture industry, ornamental fish farming has attracted attention and continues to grow in Korea, with the domestic market reaching 400 billion won in 2014 . Acheilognathinae subfamily fishes have great potential for development as ornamental fishes because of their beautiful body shape and color. Acheilognathus rhombeus, is highly favored in ornamental fish farming because of its large body size among the Acheilognathinae subfamily fishes.

A few studies have been reported on the reproduction of

\footnotetext{
Manuscript received September 20, 2019, Received in revised form October 7, 2019, Accepted October 18, 2019

${ }^{\dagger}$ Corresponding Author: Won-Kyo Lee, Dept. of Aquaculture, College of Fisheries and Ocean Sciences, Chonnam National University, Yeosu 59626, Korea. Tel: +82-61-659-7161, Fax: +82-61-659-7169, E-mail: wklee196@jnu.ac.kr
}

This is an Open Access article distributed under the terms of the Creative Commons Attribution Non-Commercial License (http:// creative-commons.org/licenses/by-nc/3.0) which permits unrestricted non-commercial use, distribution, and reproduction in any medium, provided the original work is properly cited. 
Acheilognathinae subfamily species: reproductive cycle of Rhodeus uyekii (An, 1995), sexual maturation and spawning season of the Korean Bitterling, Acheilognathus signifier in upper reaches of the Hongchen River (Baek et al., 2003), abnormality of reproduction and organ structure of the Oily Bitterling, Acheilognathus koreensis from Isa Stream (Jeong et al., 2006), change of external reproductive parameters according to sexual maturation of the Striped Bitterling, Acheilognathus yamatsutae (Jin et al., 2008), and annual reproductive cycle of Acheilognathus majusculus, a Korean endemic species (Lim \& Lee, 2017).

A. rhombeus inhabit in the rivers and reservoirs in the west and south coasts of Korea and Japan. The most studies of $A$. rhombeus reproduction have been reported in the Japanese dweller (Shimizu et al., 1987; Shimizu et al., 1994).

For species conservation and development as a new ornamental fish, we aimed to explore the reproductive cycle of Korean A. rhombeus, so as to lay grounds for artificial seedling.

\section{MATERIALS AND METHODS}

\section{Sampling}

15-20 of each female and male A. rhombeus were collected monthly from the Seomjin River, Ogok-myeon, Gokseonggun, Jeollanamdo from June 2018 to May 2019 by using weir traps and skimming nets. The collected samples were transported to the laboratory facility alive so as to be dissected carefully.

\section{Environment investigation}

Water temperature was measured every month at the sampling site. However, in order to analyze the monthly temperature precisely, we referred to Seomjin River Water Management Research Center's data. For day length, we recorded and converted the day length of every $15^{\text {th }}$ day of the month on Gokseong Meteorological Observatory database.

\section{Histological method}

Samples were measured until $0.1 \mathrm{~cm}$ unit scale for length and $0.01 \mathrm{~g}$ unit scale for weight. The ovipositor length was measured until $0.01 \mathrm{~mm}$ unit scale by using Vernier calipers. Then, the abdomen was dissected to weigh the gonads until $0.001 \mathrm{~g}$ unit scale.

We calculated the gonadosomatic index (GSI) from N' Da \& Deniel method (1993) (gonad weight/body weight $\times$ 100 ) in order to examine the monthly variation in gonad maturation status.

The dissected gonads were fixed for 24 hours in Bouin's solution (picric acid:formalin:acetic acid=15:5:1), embedded in paraffin and sliced into 5-7 $\mu \mathrm{m}$ of serial sections, and then double-stained with hematoxylin and eosin. The female reproductive cycle was defined by using the frequency of follicular development stages in the ovaries, while male reproductive cycle was defined using frequency of lobules with the progress of spermatogenesis stages in the testis.

\section{RESULTS}

1. Monthly variation in water temperature and day length

Monthly variation in water temperature and day length of the sampling site are presented in Fig. 1A. At the onset of study, water temperature was $26.2^{\circ} \mathrm{C}$ in June 2018 . It increased to $30.2^{\circ} \mathrm{C}$ in July and $30^{\circ} \mathrm{C}$ in August 2018 . The temperature dropped from $24.7^{\circ} \mathrm{C}$ in September to $16.9^{\circ} \mathrm{C}$ in October, then $11.7^{\circ} \mathrm{C}$ in November, and $5.2^{\circ} \mathrm{C}$ in December 2018. The lowest temperature was recorded $3.3^{\circ} \mathrm{C}$ in January 2019 . It bounced back to $5.5^{\circ} \mathrm{C}$ in February then $11.2^{\circ} \mathrm{C}$ in March, $15.0^{\circ} \mathrm{C}$ in April and $22.5^{\circ} \mathrm{C}$ in May 2019 .

The day length was 14.5 hours in June 2018, the longest of the year. It decreased gradually to 14.3 hours in July, 13.5 hours in August, 12.4 hours in September, 11.3 hours in October, 10.4 hours in November and 9.8 hours in December 2018, the shortest of the year. Afterwards, the 


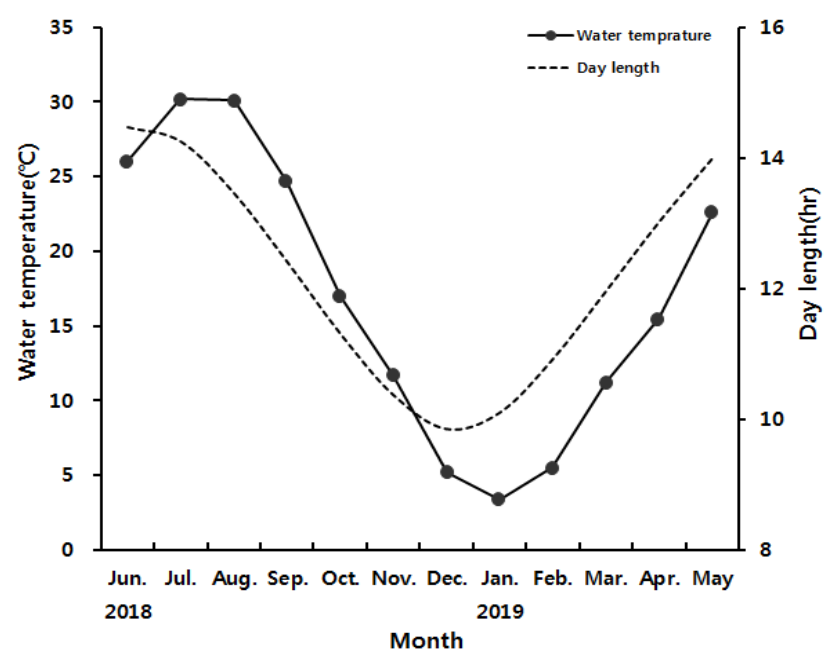

Fig. 1. Monthly variations of water temperature and day length from June 2018 to May 2019.

day length increased gradually to 10.1 hours in January 2019, 10.9 hours in February, 11.9 hours in March, 13 hours in April and 13.9 hours in May 2019.

\section{Monthly variation in gonadosomatic index (GSI)}

The annual changes in GSI of $A$. rhombeus are shown in Fig. 2. In female, the value of GSI was $1.48 \pm 0.26$ in June, increased gradually to $2.50 \pm 0.56$ in July, $3.02 \pm 0.82$ in August, 3.38 \pm 1.10 in September and 3.50 \pm 0.54 in October 2018, the highest of during the experiment periods. After

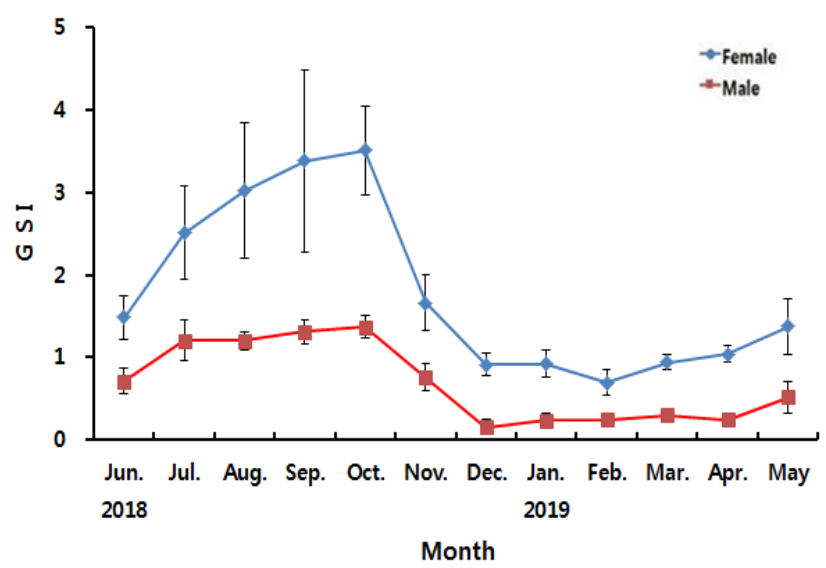

Fig. 2. Gonadosomatic index (GSI) of Korean flat bitterling, Acheilognathus rhombeus from June 2018 to May 2019. then, the value of GSI decreased abruptly to $1.66 \pm 0.34$ in November, $0.91 \pm 0.13$ in December 2018, $0.92 \pm 0.16$ in January and $0.69 \pm 0.15$ in February 2019, the lowest of during the experiment periods. Following that, the value of GSI increased gradually to $0.94 \pm 0.09$ in March, $1.04 \pm 0.09$ in April and 1.37 \pm 0.34 in May 2019. In male, the value of GSI was $0.71 \pm 0.0 .14$ in June, increased gradually to $1.20 \pm 0.24$ in July, $1.21 \pm 0.10$ in August, $1.31 \pm 0.14$ in September and $1.36 \pm 0.14$ in October 2018, the highest of during the experiment periods. After then, the value of GSI decreased abruptly to $0.75 \pm 0.16$ in November, $0.16 \pm 0.09$ in December 2018, the lowest of during the experiment periods. The value of GSI remained $0.23 \pm 0.09$ in January, $0.25 \pm 0.01$ in February, $0.30 \pm 0.04$ in March and $0.25 \pm 0.02$ in April and re-increased to $0.52 \pm 0.19$ in May 2019 .

3. Histological changes of the ovaries and reproductive cycle

The development stages of oocytes and follicles were histologically examined (Fig. 3), calculated as frequencies and female reproductive cycle (Fig. 4).

The maturing phase with primary, secondary and tertiary yolk globules oocytes appeared from April to September. The primary yolk globule oocytes appeared in the ovary from April to July, the frequency of which was $30 \%$ in April, $15 \%$ in May, $10 \%$ in June and $5 \%$ in July. The secondary yolk globule oocytes appeared in the ovary from May to August, the frequency of which was, $15 \%$ in May, $10 \%$ in June, $5 \%$ in July and $10 \%$ in August. The frequency of tertiary yolk globule oocytes was $15 \%$ in May, 35\% in June, 65\% in July, 75\% in August, 70\% in September, 10\% in October and in November. The ripe (hydrated) stage oocytes appeared from September to November, the frequency was $20 \%$ in September, $60 \%$ in October and $20 \%$ in November. In October and November, the ovulated follicles appeared in the ovary, the frequency of which was $15 \%$ In October and $10 \%$ in November. In November and December, atretic follicles appeared in the ovary. The 

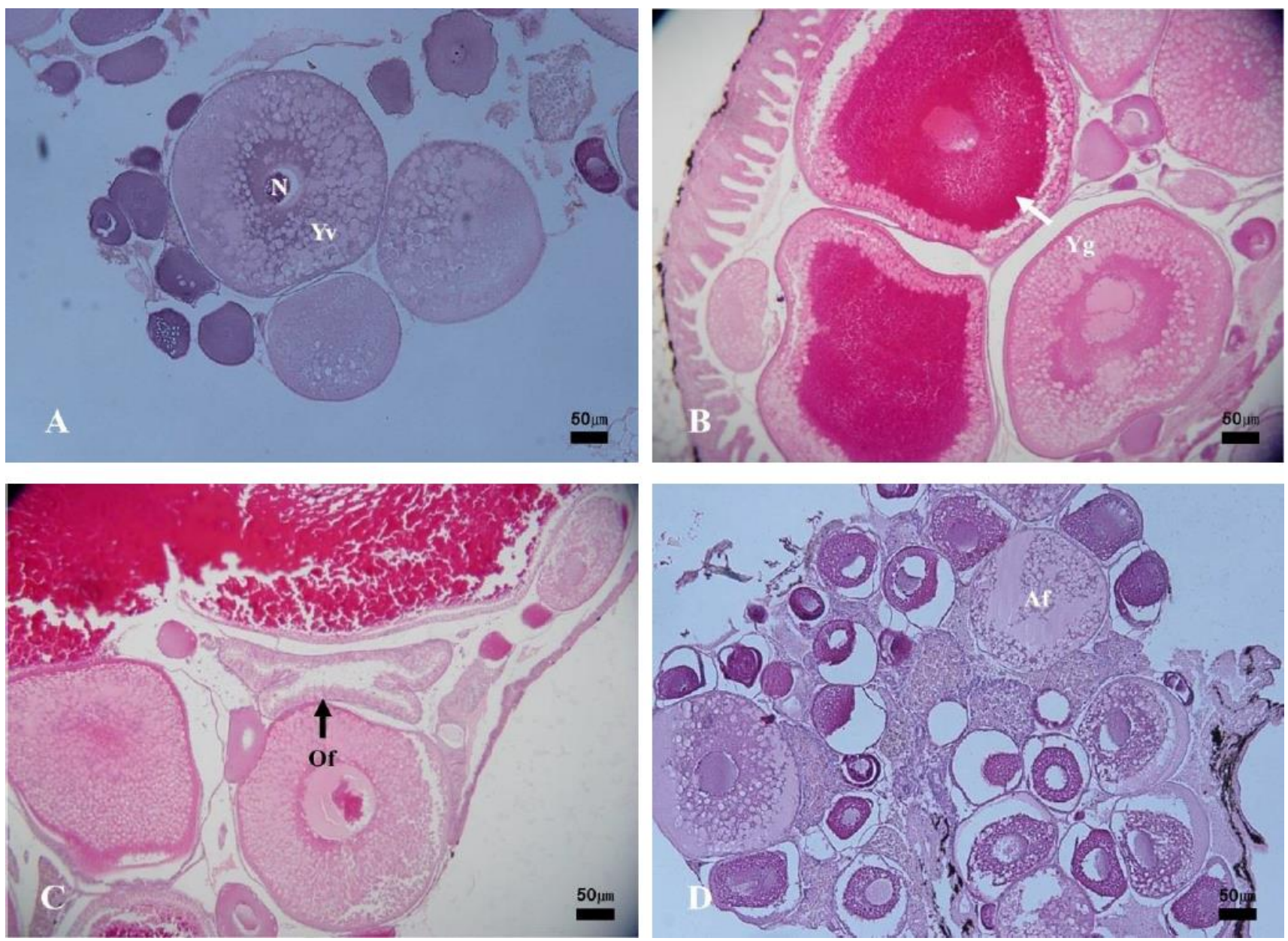

Fig. 3. Ovarian development stage of the flat bitterling, Acheilognathus rhombeus. (A) Growing phase. Note the oocytes in peri-nucleolus and yolk vesicle- stages. (B) Mature phase. Note yolk globule stage oocytes in the ovary. (C) Ripe and Spawning phase. Note the fully grown oocyte and ovulated follicle in the ovary. (D) Degenerative phase. Showing the atretic follicles. N, nucleus; Yv, yolk vesicle; Yg, yolk globule; Of, ovulated follicle; Af, atretic follicles. Scale bars: $50 \mu \mathrm{m}$.

frequency of atretic follicles was $10 \%$ In November and $5 \%$ in December.

In the female reproductive cycle, the resting phase represented only chromatin-nucleolus and peri-nucleolus oocytes in the ovary. The growing phase was the appearance of yolk-vesicle oocytes in the ovary. The yolk-vesicle oocytes appeared all around the year, and there were 5\%$25 \%$ of follicles in the ovary.

The frequency of chromatin-nucleolus and peri-nucleolus oocytes was $30 \%$ in June, $15 \%$ in July, $5 \%$ in August, $5 \%$ in September, $5 \%$ in October, $40 \%$ in November, $70 \%$ in December 2018, 90\% in January 2019, 85\% in February,
85\% in March, 50\% in April and 45\% in May.

\section{Histological changes of the testes and reproduc-} tive cycle

The progress of spermatogenesis stages in the testis were histologically examined (Fig. 5), calculated as frequencies and male reproductive cycle (Fig. 6).

The maturing phase of male with meiotic cells and spermatozoa in seminiferous tubules was observed from June to November, the frequency of spermatozoa was $20 \%$ in June, $40 \%$ in July, $55 \%$ in August, $70 \%$ in September, $75 \%$ in October and $75 \%$ in November. From August to 


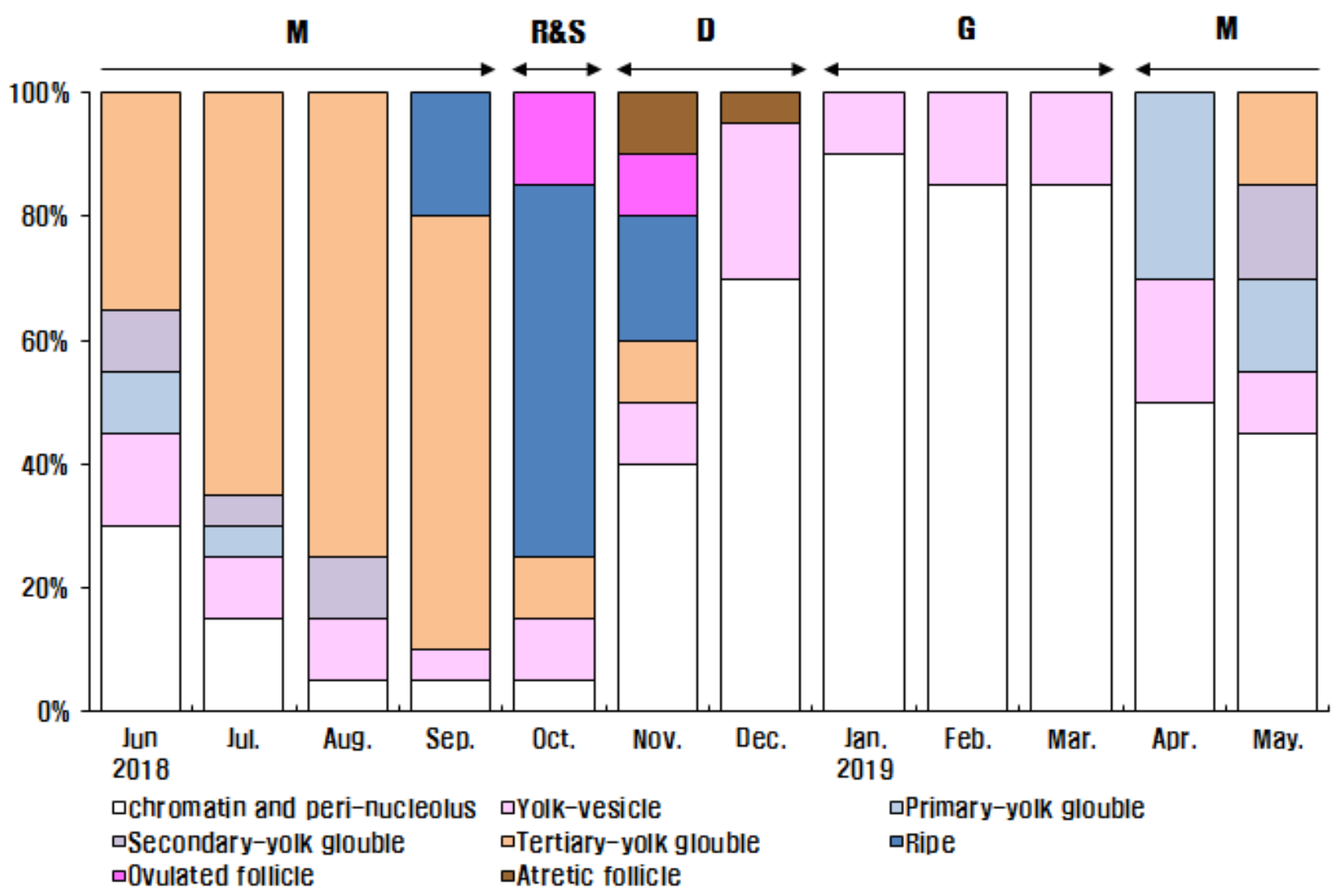

Fig. 4. Monthly change in proportional frequency of the ovarian stage in Acheilognathus rhombeus, from June 2018 to May 2019. M, mature phase; R \& S, ripe and spawning phase; D, degenerative phase; G, growing phase.

October, however, the proximal region of the sperm duct, which is directly connected to the testis, was expanded and filled with spermatozoa. In November, almost all males showed degradation and termination of spermatogenesis, although many spermatozoa remained in the lumen.

The ripe and releasing phase of the male reproductive cycle represented the seminiferous tubules filled with only spermatozoa. However, the ripe and releasing phase did not appear in A. rhombeus. From December to March, the seminiferous tubules of testis shrunk and a small amount of residual sperm remained in the lumen. Testicular spermatogonia appeared all year-round. In April, the proliferating spermatogonia were the only germ cells in the testis and onset a new reproductive cycle. In May, small tubules containing spermatogonia, spermatocytes and spermatid appeared. The frequency of primary spermatocyte, secondary spermatocyte and spermatid were 15\%, 40\%, and $35 \%$, respectively.

\section{DISCUSSION}

Most fish is spawn in the period of maximal possibility of offspring survival, since successful prosperity is the key strategy for species continuity. Fishes that inhabit middle latitude regions have seasonal spawning phase, and they repeat annually (Lee et al., 1984; Ki \& Lee, 2018). The sexual maturity and annual reproductive cycles of fish are established through the value of GSI and progress of gamatogenesis in the gonads.

The GSI of Acheilognathinae subfamily fish is highest right before or in the start of spawning, and maintains relatively high levels during spawning. However, immediately 

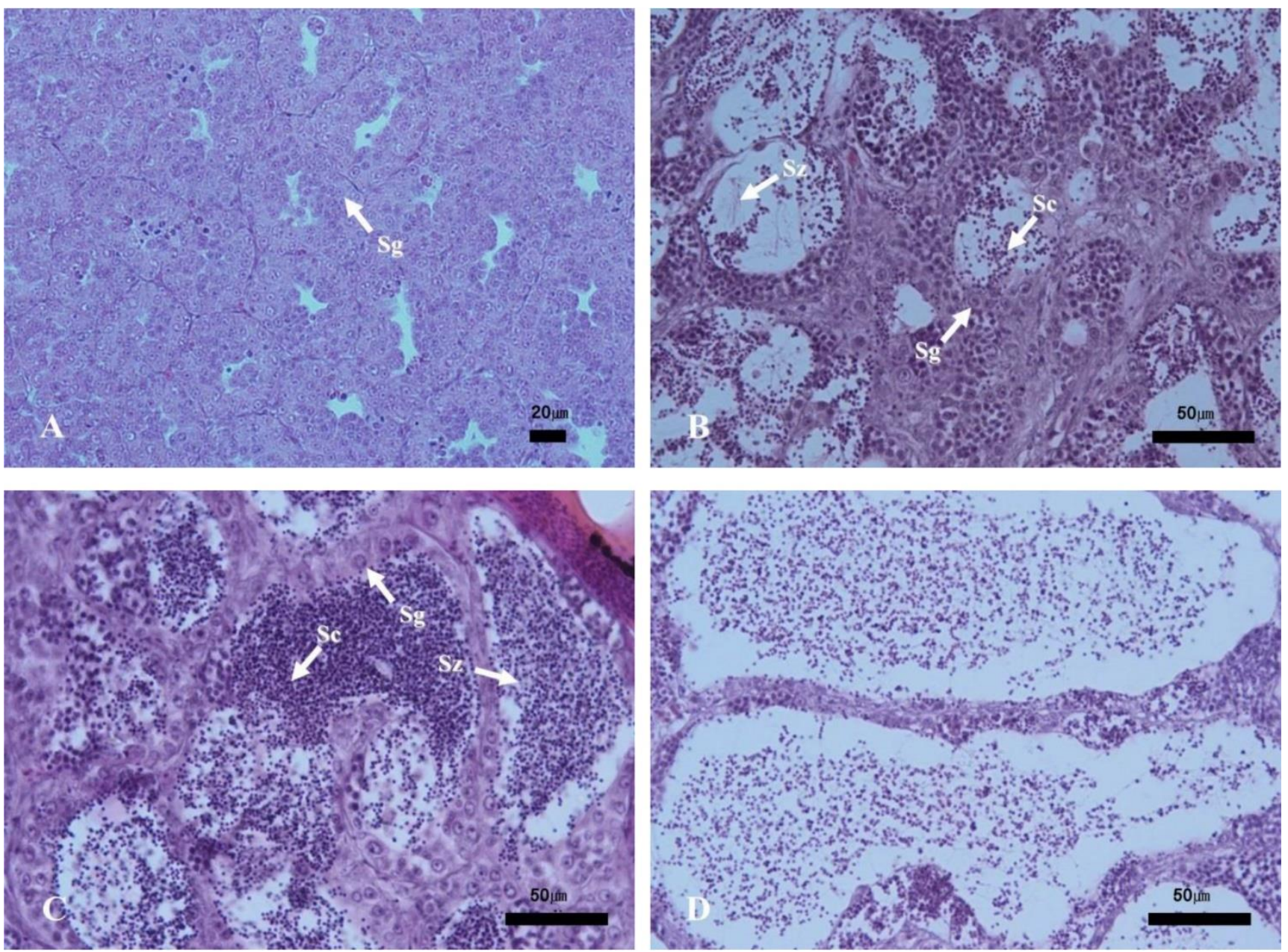

Fig. 5. Testicular development stage of the flat bitterling, Acheilognathus rhombeus. (A) Resting phase. The testes filled with dividing spermatogonia. (B) Mature phase. Spermatogonia, spermatocyte, spermatid and spermatozoa filled the seminiferous tubule in August. (C) Mature phase. The testis in September. (D) degerative phase. Sg, spermatogonia; Sz, spermatozoa; Sc, spermatocyte; St, spermatid. Scale bars: 20-50 $\mu \mathrm{m}$.

after the process, the GSI drops to the annual lowest, with gradual rebound. However, the timing and duration are different from species to species. In the female of the Acheilognathinae subfamily fish, the highest level of GSI was 9.83 in Rhodeus uyekii (May), 14.60 in A. koreensis (December), 6.95 in Acheilognathus signifier (April), 18.1 in A. yamatsutae (February), 19.21 in A. majusculus (April), 7 in Japanse A. rhombeus (October) and 3.50 in Korean A. rhombeus (October), respectively (An, 1995; Baek et al., 2003; Jeong et al., 2006; Jin et al., 2008; Lim \& Lee, 2017; Shimizu et al., 1987). These differences in GSI are likely due to genetic differences between species.
In the males of Acheilognathinae subfamily fish, the highest level of GSI was about 4 in Rhodeus uyekii (April), 6.13 in A. koreensis (April), 2.84 in Acheilognathus signifier (April), 5.48 in A. yamatsutae (February), 5.02 in A. majusculus (May), about 2 in the Japanese A. rhombeus (October) and 1.36 in the Korean A. rhombeus (October), respectively (An, 1995; Baek et al., 2003; Jeong et al., 2006; Jin et al., 2008; Lim \& Lee, 2017; Shimizu et al., 1987). The level of the highest GSI value in males differed among the Acheilognathinae subfamily fishes and was lower than that of females. There was coincidence with the timing of the peak of GSI in both females and males in 


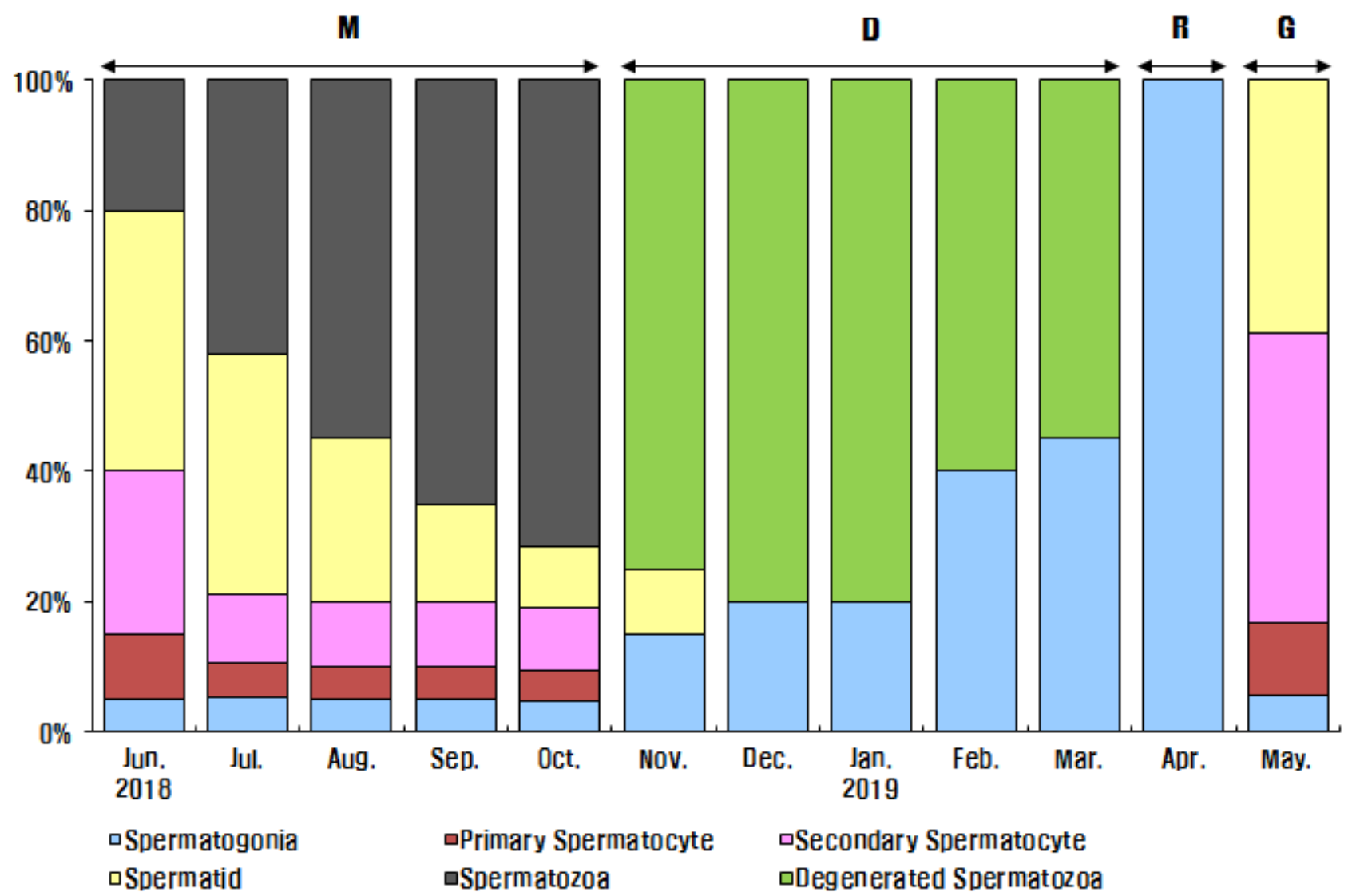

Fig. 6. Monthly changes in proportional frequency of testicular stage in Acheilognathus rhombeus, from June 2018 to May 2019. M, mature phase; $D$, degenerative phase; $R$, resting phase; $G$, growing phase.

Acheilognathus signifier, A. yamatsutae and A. rhombeus, but not in other species.

While investigating the sexual maturation of gonads, the female Aceilognathus rhombeus showed only chromatinnucleolus, peri-nucleolus and yolk vesicle from January to March. The maturing phase with the primary, secondary and tertiary yolk globules oocytes in the ovary appeared from April to September. The ripe and spawning phase with the hydrated oocytes and ovulated follicles in the ovary was found in October. From November to December, the ovary showed atretic follicles. From September to November, artificial egg collection by using the abdominal compression method was possible only in October (result not shown). The yolk vesicle oocytes appeared almost all year round in the ovary. We concluded that female A. rhombeus's reproductive cycle shows four phases without a distinctive resting phase. These phases are growing phase (January to March), and mature phase (April to September), ripe and spawning phase (October), and degenerative phase (November to December). Among the species of Acheilognathinae, the annual reproductive cycle of Aceilognathus rhombeus showed four phases without the resting phase as like $A$. majusculus (Lim \& Lee, 2017).

In males, the seminiferous tubules of testis were filled with meiotic cells and spermatozoa from June to November. From December to March, the seminiferous tubules of the testes shrunk and a small amount of residual sperm remained in the lumen. In April, the dividing spermatogonia were the only germ cells in the testis and onset a new reproductive cycle. The meiotic germ cells, spermatocyte and spermatid appeared in May. The annual reproductive cycle of male A. rhombeus was categorized into four 
phases: which are the mature phase (June to October), degenerative phase (November to March), resting phase (April), and growing phase (May). The ripe and releasing phase did not appear and the spermatogonia showed all year-round. However, from August to October, the proximal region of the sperm duct, which is directly connected to the testis, expanded and was filled with the spermatozoa.

Fish can be classified into five categories in respect of their spawning phase - spring spawner, spring-summer spawner, summer spawner, autumn spawner, spring/autumn spawner and winter spawner (Aida, 1991). For the Acheilognathinae subfamily, three categories have been identified to date, which are spring spawner, summer spawner, and autumn spawner (Asahina et al., 1980; Shimizu \& Hanyu, 1981; Shimizu \& Hanyu, 1993; Song \& Kwon, 1989). The Korean A. rhombeus showed the characteristics of autumn spawner as like Japanese $A$. rhombeus. However, in A. rhombeus, the value of GSI of female fish was different between the Japanese dweller and Korean inhabitant even if they are of the same species (Shimizu et al., 1987). The reason of the difference in GSI may be due to different habitats. The Japanese and Korean fishes were collected from ponds and streams, respectively. However, further research will have to be carried out.

The reproductive cycle of fish is affected by external factors, such as water temperature and day length. The initiation of the spawning in the autumn spawner mainly depends on the shortening of day length and secondarily on decreasing temperature in fall. The termination of spawning phase is caused by decreasing temperature in late autumn or in winter (Aida, 1991; Shimizu et al., 1994). The day length was 12.4 hours in September, 11.31 hours in October and 10.37 hours in November. The water temperature of the sampling site was $24.7^{\circ} \mathrm{C}$ in September, $16.9^{\circ} \mathrm{C}$ in October and $11.7^{\circ} \mathrm{C}$ in November.

Fish could be classified as synchronous, groupsynchronous and asynchronous based on oocyte development in the ovary (Wallace \& Selman, 1981). Synchronous development only have one type of developing oocyte within the ovary, and when it matures it ovulates once at a specific timing. Group-synchronous development has two distinct oocyte under development. Asynchronous development has various types of oocytes within the ovary, a characteristics of multiple-spawning fish species (Shimizu et al., 1994). Rhodeus uyekii (An, 1995) and Acheilognathus signifer (Baek et al., 2003) and A. majusculus (Lim \& Lee, 2017) are asynchronous development type with multiple spawning habit, while $A$. koreensis is a group-synchronous development type with single spawning habit (Jeong et al., 2006). A. rhombeus showed various types of oocytes within the ovary during the spawning phase in October and represent the typical asynchronous development of oocytes.

This study hopes to contribute to species preservation and development of a new ornamental fish by defining the reproductive cycle of $A$. rhombeus.

\section{ORCID}

\section{Se-Un Ki}

https://orcid.org/0000-0003-2842-000X

\author{
Kang-Hee Kho \\ https://orcid.org/0000-0001-8731-6101
}

\author{
Won-Kyo Lee \\ https://orcid.org/0000-0002-0303-3129
}

\section{CONFLICT OF INTEREST}

The authors declare no potential conflict of interest.

\section{AUTHOR CONTRIBUTIONS}

Conceptualization: Lee WK.

Data curation: Ki SU, Lee WK.

Formal analysis: Ki SU. 
Methodology: Ki SU, Lee WK.

Software: Ki SU.

Validation: Kho KH.

Investigation: Ki SU.

Writing - original draft: Ki SU, Lee WK.

Writing - review \& editing: Kho KH, Lee WK.

\section{ETHICS APPROVAL}

This article does not require IRB/IACUC approval because there are no human and animal participants.

\section{REFERENCES}

An CM (1995) Reproductive cycle of the spring-spawning bitterling, Rhodeus uyekii (Pisces: Cyprinidae). Korean J Ichthyol 7:33-42.

Aida K (1991) Environmental regulation of reproductive rhythms in teleostes. Bull Inst Zool Acad Sin Monogr 16:173-187.

Asahina K, Hanyu I, Iwashita I, Hibiya K (1980) Annual reproductive cycle of a bittering, Rhodeus ocellatus ocellatus. Bull Jpn Soc Sci Fish 46:299-305.

Baek HM, Song HB, Kwon OK (2003) Sexual maturation and the spawning season of the Korean bitterling, Acheilognathus signifier in upper reaches of the Hongcheon River. Korean J Ichthyol 15:278-288.

Jin YG, Kim CH, Lee CW, Kim JW, Lee JS (2008) Change of external reproductive parameters according to sexual maturation of the striped bitterling, Acheilognathus yamatsutae (Teleostei: Acheilognathinae). Korean J Ichthyol 20:13-20.

Jeong SY, Shin SH, Jin YG, Ju SM, Lee JS (2006) Abnormality of reproduction and organ structure of the oily bitterling, Acheilognathus koreensis from Isa stream. Korean J Ichthyol 18:87-96.

Ki SU, Lee WK (2018) The annual reproductive cycle of Silurus microdorsalis, a Korean endemic species. Dev
Reprod 22:1-8.

Kim IS, Choi Y, Lee CL, Lee YJ, Kim BJ, Kim JH (2005) Illustrated Book of Korean Fishes. Kyohak, Seoul, p 615.

Lee TY, Hanyu I, Furukawa K (1984) Effects of photoperiod and temperature on the gonadal activity in small filefish, Rudarius ercodes. Korean J Fish Aquat Sci 17:523-528.

Lim JY, Lee WK (2017) Annual reproductive cycle of Acheilognathus majusculus, a Korean endemic species. Dev Reprod 21:297-305.

N' Da K, Deniel C (1993) Sexual cycle and seasonal changes in the ovary of the red mullet, Mullus surmuletus, from the southern coast of Brittany. J Fish Biol 43:229244.

Shimizu A, Aida K, Hanyu I (1987) Annual reproductive cycle in an autumn-spawning bitterling Acheilognathus rhombea. Bull Jpn Soc Sci Fish 53:529-536.

Shimizu A, Aida K, Hanyu I (1994) Effects of photoperiod and temperature on gonadal activity and plasma steroid levels in an autumn-spawning bitterling, Acheilognathus rhombea, during different phase of its annual reproductive cycle. Gen Comp Endocrinol 93:137-150.

Shimizu A, Hanyu I (1981) Annual reproductive cycle of a spring-spawning bittering, Acheilognathus tabira. Bull Jpn Soc Sci Fish 48:1563-1568.

Shimizu A, Hanyu I (1993) Factors involved in the development of and decline in photoperiodism as it relates to the gonadal activity of spring-spawning bitterling, Acheilognathus tabira. J Exp Zool 265:134143.

Song HB, Kwon OK (1989) Study on the deposition and development characters of Acheilognathus yamatsutae Mori (Cyprinidae) from the lake Uiam. Korea J Limnol 22:51-70.

Wallace RA, Selman K (1981) Cellular and dynamic aspects of oocyte growth in teleosts. Am Zool 21:325343 . 